\title{
Cross-cultural communication ability model in English major of the CDIO evaluation
}

\author{
Liyun Liu
}

Zhengzhou university of industrial technology.Henan.China

\section{Keywords: CDIO-based;English major;E-learning pattern}

\begin{abstract}
In view of such a common phenomenon that the CDIO-based learning method is unable to guarantee high learning quality, this paper proposes a knowledge unit-based learning quality evaluation model in English major that is adapted to the CDIO environment based on the fuzzy comprehensive evaluation method with the combination of the characteristics of the classroombased learning pattern. The result of the teaching experiment proves that this model in English major is able to enhance efficiently the ability of the learning feedback acquisition and the processing capacity of an e-learning system, promoting the collaboration between the on-line educators and strengthening the learning quality monitoring function provided by the educator. It has played a significant role in the improvement of the knowledge unit-based learning quality. Hence, this model in English major will have a promising prospect of application with the rapid development of the CDIO-based learning pattern.

Recently the three e-learning courses released by Stanford University, have opened the door to the CDIO (massive open online courses) era ${ }^{[1,2]}$. With millions of registered users are participating in the CDIO every year and the market having been growing at a rate near to $23 \%{ }^{[2]}$, which has promoted the M-learning to act as a pioneer in the "education revolution" ${ }^{[3-5]}$. However, the course completion rate is only 7\%-9\% on the Coursera website, where most of data is about the learners who have obtained the relevant degree ${ }^{[6]}$, forcing the researchers to think about the problems of the CDIO itself more soberly.

M-learning has been conducted mainly through the online video and the online testing ${ }^{[7]}$, where the learners and the educators are isolated from each other ${ }^{[8]}$. Since it focuses on the approach that the learners can acquire knowledge during their learning, ignoring the approach that the educators might get the teaching feedback, then the online educators might lose the control over the learning quality since they are unable to evaluate the learning quality of the learners about the target knowledge, nor could they make a specific adjustment on the content and the strategy based on the evaluation result. Then due to the lack of target, the learners can hardly feel a sense of integration and that they' re concerned about. Hence the learners' persistence in learning activities always puts them on their mettle.

As shown in Fig.1, the approach that the students acquire knowledge forms a closed knowledge flow loop with the approach that the teacher gets the feedback in a classroom environment ${ }^{[9]}$. The purpose that the teachers should collect the teaching feedback is to evaluate the current learning quality of the learners ${ }^{[10]}$, so as to adjust their teaching content and strategy to control the learning quality within the expected range based on the evaluation result. At this moment, the teacher will work like a "quality inspector" in the assembly line of the factory. Actually the learning quality evaluation made by the teacher can be grouped into the curriculum-based evaluation and the knowledge unit-based evaluation in a classroom environment. The knowledge unit-based learning quality evaluation, which is conducted in the classroom teaching process, has not only become one of the important sources that make the students feel a sense of integration and that they' re concerned about, but also become a fundamental link in the control of teaching quality.
\end{abstract}




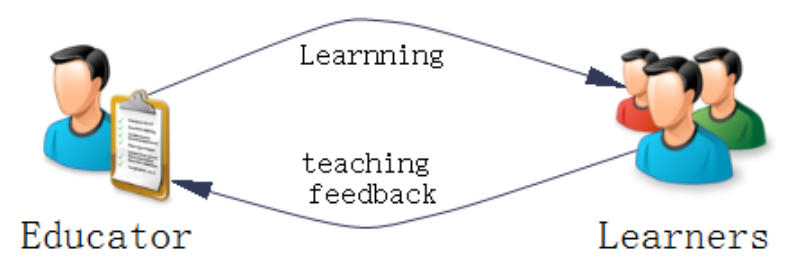

Fig.1. Knowledge flow loop in a classroom

The knowledge unit-based learning quality evaluation consists of the following three parts, including the student's subjective evaluation, the assessment on the procedural learning material and the assistant's or the teacher's subjective self-evaluation. The student's subjective evaluation result will be fed back to the relevant teacher through the following classroom exchange methods including the students' movements, their facial expression, their questions and discussion when the students are attending the class. However the assessment on the procedural learning material is reflected in the teacher's daily work, such as the check of the study notes, the homework correcting, the experimental report, the unit test and the paper etc. As to the assistant's or the teacher's subjective self-evaluation, it's the evaluation made by the teacher, who acts as the third party on the teaching process, including the completeness of the target knowledge that has been taught, the degree that the background knowledge has been elaborated and the comprehensiveness of the training tasks, which even cover the training of various abilities. The evaluation results from these three aspects finally bring about a relatively comprehensive evaluation result with the combination of the teacher's working experience.

\section{Solution Design}

In this CDIO era, there're big differences between the M-learning and the classroom learning, such as the early preparation for the video recording, the large number of learners and the discreteness of the learning time and places ${ }^{[8]}$ etc. Therefore it's impossible that the knowledge-unit based learning quality evaluation can be made independently by the educators that are shown in the video. On account of this, this paper proposes a mathematical algorithm for the comprehensive knowledge unit-based learning quality evaluation model in English major based on the fundamental features of the CDIO-based learning. Then based on such a model in English major , this paper designs a solution for the experimental e-learning system that is applicable to the CDIO environment and capable to collect teaching feedback, make learning quality evaluation and support the strategy adjustment.

The target users of this experimental system include the online educators, the learners, the evaluator for procedural materials and the learning quality facilitator. The role function of the online educator has been defined simply, which refers to the video resources contributed by the system to the e-learning courses.

The learner, which is the core and the target user of the system, is able to use the following functions including the support for the e-learning, the input of the procedural materials, review and maintenance as well as the subjective evaluation on the effect of the knowledge unit-based learning.

The evaluator for procedural materials is responsible for the evaluation on the subjective procedural learning materials including the online study notes created by the learners, their homework, the experimental report, the paper and the design works etc. in addition to the provision of the relevant revision suggestion. As to the objective procedural learning materials, they will be assessed by the evaluation system.

The learning quality facilitator is the core organizer of the e-learning process, responsible for the subjective evaluation on the teaching process and the strategy adopted in the video with the utilization of the knowledge unit-based learning quality evaluation model in English 
major to make a comprehensive assessment on the learners on a group basis. Then the facilitator will make a reasonable adjustment on the strategies, such as the supplement of the learning materials including the video, text or animation etc. to provide more practices or tasks and initiate a discussion with hints within the learning group according to the comprehensive evaluation result and the membership matrix of the evaluation indexes. The facilitator will execute the comprehensive evaluation and adjustment strategy repeatedly until the learning quality conforms to the expected result.

\section{Mathematical model in English major}

The learning quality evaluation index system consists of the objective indexes and the subjective indexes. Since all of the indexes are rather fuzzy, then this paper chooses the fuzzy comprehensive evaluation (FCE for short) ${ }^{[11]}$ to construct a learning quality evaluation model in English major . However in order to avoid the great difference in the human factors for the evaluation index weights, this model in English major adopts the analytic hierarchy process (abbreviated as AHP) to calculate the weight vector of the evaluation index se ${ }^{\mathrm{t}[12]}$.

\subsection{Index Set}

As shown in Figure 2, this paper has built a hierarchical structure where knowledge unit is considered as the evaluation target with the combination of the composition characteristics of the assessment on the knowledge unit-based learning effect and the features of the CDIO-based learning in the classroom learning mode. Assume that the set of the rule hierarchy is $\mathrm{C} 0=\{\mathrm{C} 1, \mathrm{C} 2, \mathrm{C} 3\}$, then the indicator-based evaluation will contain three subsets, including $\mathrm{C} 1$, the subset for the assessment on the learning materials, C3 the subset for the subjective evaluation made by the online teaching assistant and $\mathrm{C} 2$ the subset for the learner's subjective evaluation. $\mathrm{C} 1=$ \{OSN, OH, OT, ER, PP, TA $\}$

C2= $\{$ IBK, IBKT, AS, CETK, TAQDP, TIA,TCBS, TCMS $\}$

$\mathrm{C} 3=\{\mathrm{DCTK}, \mathrm{AR}, \mathrm{DCBK}, \mathrm{TSQEM}, \mathrm{KMOMG}\}$

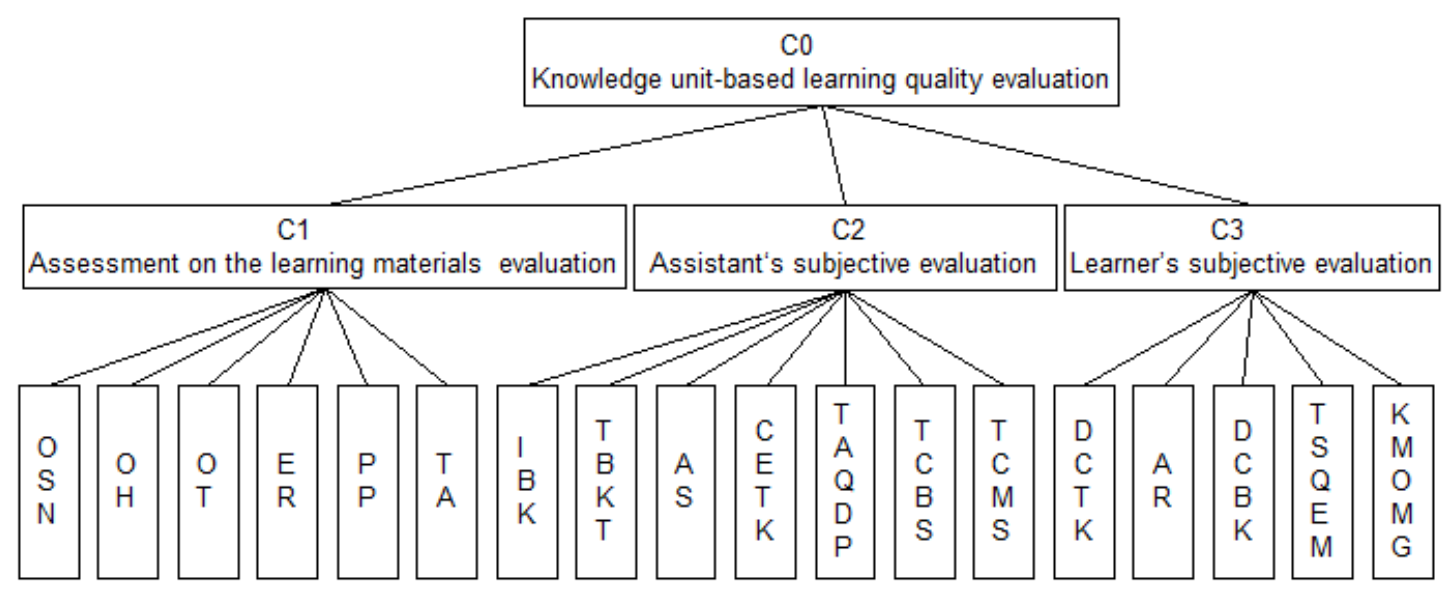

Fig. 2 Knowledge unit-based learning quality evaluation index system

In the knowledge unit-based learning quality evaluation model in English major , the degree that the learner should master all of the knowledge points in the target knowledge unit is considered as the evaluation object. By virtue of the relevant e-learning system, this model in English major has integrated the e-learning and the feedback process as a whole to avoid the shortcoming in the traditional e-learning system that focuses on the learning procedure, neglecting the feedback information. Therefore our model in English major is able to provide an objective basis for the online educator to guide the learners specifically about their learning process and content. Also it will make the online learners feel that they're concerned about to bring about a stronger sense of integration. Actually in the teaching experiment, our model in English major has contributed to the significant improvement of the e-learning quality. Therefore it has a promising prospect of application under such a background that the CDIO-based learning has been developed quickly. 


\section{References}

[1]Pappano, Laura. "The Year of the CDIO." The New York Times 2.12 (2012): 2012.

[2]Breslow, Lori, et al. "Studying learning in the worldwide classroom: Research into edX's first CDIO." Research \& Practice in Assessment 8.1 (2013): 13-25.

[3]Aguaded-Gómez, J. Ignacio. "The CDIO Revolution: A new form of education from the technological paradigm." Comunicar 41 (2013): 7-8.

[4]Kolowich, Steve. "The CDIO'Revolution'May Not Be as Disruptive as Some Had Imagined." The Chronicle of Higher Education 8 (2013).

[5]Friedman, Thomas. "Revolution hits the universities." The New York Times 26 (2013). 